\title{
AS REFORMAS ORTOGRÁFICAS DA LÍNGUA PORTUGUESA: UMA ANÁLISE HISTÓRICA, LINGÜÍSTICA E IDEOLÓGICA
}

Monalisa dos Reis Aguiar

RESUMO: O século XIX brasileiro é marcado por significativas mudanças políticas, sociais, econômicas. Nesse contexto, devido ao sentimento nacionalista proveniente da Independência Política, as questões da língua tornam-se motivos de discussões que ambicionavam, entre outras coisas, a independência linguística e, por consequiência, a independência ortográfica. São justamente tais questões que refletem a busca da identidade linguística do brasileiro oitocentista, que são o tema deste artigo, o qual faz parte de uma pesquisa maior.

PALAVRAS-CHAVE: Língua portuguesa; ortografia; identidade linguística; identidade nacional.

\section{CONSIDERAÇÕES INICIAIS}

ste artigo tem por objetivo analisar como se constituíram e se consolidaram as Reformas Ortográficas da Língua Portuguesa no início do século XX, estendendo-se até o primeiro Acordo Ortográfico entre Brasil e Portugal, em 1931, estudadas sob três pontos de vista: o histórico, o lingüístico e o ideológico. Para tanto, tendo como aparato teórico a História das Idéias Linguiísticas, busca-se, no que concerne à perspectiva histórica, explicitar em que medida o contexto em que foram produzidas as propostas ortográficas interferiu em sua fixação. No que diz res-

- Universidade de Mogi das Cruzes e Universidade Camilo Castelo Branco. 
peito à perspectiva linguiística, propõe-se a análise propriamente dita das regras propostas a fim de se verificar se há tendência ao predomínio do sistema fonético ou etimológico, buscando-se, evidentemente, a justificativa de suas escolhas. Por fim, no que tange à ideologia, pretende-se evidenciar como o caráter ideológico perpassa cada proposta.

Quanto ao método de desenvolvimento deste estudo, procurou-se, como propõe Auroux (1992), a definição puramente fenomenológica do objeto, a neutralidade epistemológica e o historicismo moderado, ou seja, na análise, buscou-se respeitar as terminologias usadas na época em que foi produzido o objeto, destacando-se, além dos fatos históricos, outros fatores que influenciaram o aparecimento de determinado instrumento linguiístico.

\section{A QUESTÃO ORTOGRÁFICA NO SÉCULO XIX: OS PASSOS RUMO À REFORMA}

No Brasil e em Portugal, as normas ortográficas só se fixaram de fato no século XX. Com o avanço da escolarização obrigatória e a proliferação dos meios de comunicação de massa tornou-se imperioso ter, em cada país, uma forma unificada de escrever.

Alguns fatos políticos e sociais como a abolição, a Independência e a República fizeram aflorar no Brasil um forte sentimento nacionalista. Emerge, nesse período, um movimento de valorização da cultura e de nacionalismo linguiístico. Surgem, com isso, as primeiras manifestações ligadas à política de um idioma nacional em busca da identidade linguiística brasileira. Desse modo, houve quem defendesse a existência de duas línguas: uma portuguesa e outra brasileira, confundindo-se variedade de uma mesma língua com o aparecimento de um novo sistema. A questão da língua reflete-se também na questão ortográfica, pois a tentativa de uma língua brasileira resulta, consequientemente, na busca de uma ortografia brasileira. 
A questão ortográfica, associada à independência e à busca pela identidade nacional, passa a ser o cerne das discussões entre alguns estudiosos da época, demonstrando, embora em graus variáveis, o desejo e a intenção de se adquirir a autonomia linguiística no Brasil. No entanto, mesmo num período tão marcado por questões nacionalistas e identitárias, alguns autores defendem a manutenção da língua como legado de Portugal. A questão ortográfica tinha um caráter que ia além da tentativa de simplificar e fixar a ortografia: adquire um forte cunho nacionalista, sobretudo, pelas marcas que diferenciam a pronúncia brasileira em relação à pronúncia européia, intensificando-se, desse modo, a busca da identidade nacional por meio da criação de um sistema gráfico brasileiro.

Destacam-se José Jorge Paranhos da Silva e Miguel Lemos como defensores desse ponto de vista. Porém, havia aqueles que se preocupavam em manter a tradição, como é o caso de José Feliciano de Castilho e José Ventura Bôscoli, representantes de posicionamento oposto ao dos autores referidos acima.

Em seus postulados, José Jorge Paranhos da Silva defende a suposta língua brasileira por meio do estudo comparativo entre as pronúncias do português brasileiro e europeu, estabelecendo, desse modo, diferenças que para ele são significativas a ponto de justificarem a independência linguíística. Propõe, inclusive, que sejam traduzidas as poesias escritas em língua portuguesa para a língua brasileira.

As idéias de Paranhos da Silva não tiveram o impacto que ele gostaria, principalmente em Portugal, onde foram pouco comentadas. Parece que, embora sua intenção fosse oferecer maior facilidade e clareza nos escritos do Brasil, faltava-lhe conhecimento teórico acerca do assunto. Desse modo, sua tentativa de contribuir para a solução dos problemas ortográficos é ofuscada pelos exageros e pela confusão. Miguel Lemos, com sua "ortografia brasileira” (1884, p. 10) também propõe uma grafia que represente o falar brasileiro, cuja finalidade é "emansipar o público, sobretudo a parte infantil, proletária i feminina, dos obstáculos tradissionais que o pedantis- 
mo gramatical érgue continuamente à instrussão das massas populares".

A ausência de base científica evidencia-se na maioria dos autores citados que não são filólogos. Muitas das regras que propõem são marcadas por equívocos em relação a dialeto, língua, uso e ao estilo. Outras estão despojadas de qualquer preocupação histórica, pois abusam de grafias baseadas nas grafias grega e latina e letras geminadas, sem nenhum fundamento, como é o caso de José Feliciano de Castilho e José Ventura Bôscoli.

Em Portugal, duas propostas são de fundamental importância para a realização da reforma ortográfica: a ortografia fonética de José Barbosa de Leão (1875) e o empenho de Aniceto dos Reis Gonçalves Viana e Guilherme Augusto de Vasconcelos Abreu (1885) rumo a uma ortografia simplificada. José Barbosa Leão publicou, no final de 1875, uma obra intitulada Consideraçõis Sobre a Orthographia Portugueza. Devido ao fato de acreditar que a mudança deveria vir "de cima para baixo", ofereceu sua obra ao Conselheiro António Rodrigues Sampaio, ministro dos Negócios do reino. Além disso, ele a distribuiu pelas repartições públicas e os institutos de ensino superior, especial e secundário, e enviou-a também para a Academia Real das Ciências.

Sua intenção era que o ministro exigisse de cada um dos conselheiros dos liceus um parecer sobre a reforma proposta e que esses pareceres fossem publicados no Diário do Governo. Assim também esperava que acontecesse na Academia, porém, seu desejo não se concretizou, pois a Junta constitutiva da Instrução Pública se opôs ao projeto, sugerindo que também o ministro o rejeitasse.

Acreditando ter percorrido o caminho errado, decidiu fazer "a revolução de baixo para cima". Devido a seus esforços surgiram os convênios e a constituição da Comissão do Porto. Prosseguiu sua proposta publicando, em 1878, a Coleção de Estudos e Documentos a favor da Reforma Ortográfica em Sentido Sônico, na qual constam representação da Academia Real das Ciências e o Parecer da Comissão de Reforma Ortográfica. 
Esforçou-se esse estudioso por promover uma reforma no sistema ortográfico e acabou por conseguir alavancar um movimento em favor da reforma por meio de uma reunião pública, na qual foi eleita uma comissão incumbida de estudar essa possibilidade. Como resultado, em 23 de dezembro de 1877, a Comissão do Porto apresentou o Parecer da Comissão de Reforma Ortográfica aceitando o estabelecimento da proposta.

Apenas em 5 de fevereiro de 1878 foi apresentado à Academia das Ciências o Parecer, cuja análise deveria ser feita por uma comissão formada por cinco acadêmicos especialmente nomeados. Um ano depois, Latino Coelho, um dos acadêmicos, após ter lido metade do parecer na sessão de 6 de junho de 1879, apresentou o seu Parecer dizendo ser uma proposta inviável, de impossível aceitação, visto se tratar de uma ortografia sônica, ou seja, de visão individual sobre o ideal de haver uma só letra para cada som e um só som para cada letra.

De outro modo, Aniceto dos Reis Gonçalves Viana, Guilherme Augusto de Vasconcelos Abreu e Zófimo Consuigliere Pedroso editaram uma coleção científica de grande divulgação chamada Enciclopédia de ciência, arte e literatura - Biblioteca de Portugal e Brasil, da qual o primeiro volume, A literatura e a Relijião dos Árias na Índia, escrito por Gonçalves Viana e Vasconcelos Abreu, foi publicado em 1885. Devido a essa publicação, os dois autores julgaram ser necessária a criação do opúsculo Bases da Ortografia Portuguesa, em 1885, que tinha por objetivo explicar quais princípios ortográficos adotaram para escrever a Coleção, visto que se tratava de uma grafia diferente daquela que vinha sendo usada até aquele momento.

Nessa obra, ao contrário do que fizeram os ortógrafos anteriores, Gonçalves Viana e Vasconcelos Abreu optaram por não denominar sua proposta ortográfica, fonética ou etimológica, mas simplesmente "Ortografia Portuguesa". Vê-se, desse modo, que os autores tentaram conciliar os dois sistemas.

Apesar da tentativa de equilíbrio entre os dois sistemas, os autores nortearam-se mais pela pronúncia do que pela etimologia, 
fato que se comprova quando reconhecem que é indispensável uma acentuação gráfica "subordinada às leis de acentuação de língua falada" (Viana/Abreu, 1885, p. 5). Tentam considerar a escrita baseada em estudos históricos, impedindo, consequientemente, que o projeto tenha o mesmo destino que o da Comissão do Porto.

Esse posicionamento pode ser justificado pela influência que receberam da linguiística histórico-comparativa. Desse modo, em confluência com essa escola, que postula, dentre outras coisas, que a língua é um fato social, os autores acreditam que também a ortografia seja um fato social; desse modo, nenhuma pessoa poderia, individualmente, introduzir mudanças de nenhuma ordem na língua.

A obra de Aniceto Reis Gonçalves Viana Ortografia Nacional: Simplificação e Uniformização Sistemática das Ortografias Portuguesas, publicada em 1904, representa um marco na história da ortografia portuguesa, visto que se trata de uma proposta baseada em minucioso estudo fonético e etimológico, diferente de alguns dos tratados anteriores, em que se determinava, sem justificativa científica ou verdadeiro estudo histórico, o uso de um grafema e não de outro. Por isso, justifica-se o fato de todos os estudos posteriores, referentes à questão ortográfica, serem baseados em suas idéias.

Seu posicionamento central é o de que a base para a regularização da ortografia portuguesa deve ser "a história da língua no tempo e no espaço" (op. cit., p. 7). Gonçalves Viana acredita que seja necessário um estudo científico dos documentos escritos desde os primeiros tempos, associado aos conhecimentos metódicos dos vários dialetos atuais. Afinal, para ele, os dialetos portugueses falados em sua época não são originados do latim literário, mas sim de outros dialetos que se falaram no território. Por causa disso, desconhecer ou menosprezar as formas portuguesas anteriores às atuais para misturá-las com o latim literário é um erro de método, pois se elimina um fator importante da evolução que é a transformação lenta e sucessiva. 


\section{A ORTOGRAFIA PORTUGUESA NO SÉCULO $X($ : DE MEDEIROS $E$ ALBUQUERQUE AO ACORDO ORTOGRÁFICO DE 1931}

Fazia-se necessária a elaboração de um sistema que fosse capaz de atingir um número maior de adeptos. É nesse contexto que a Academia Brasileira de Letras, por proposta de José Medeiros e Albuquerque, tenta estabelecer a primeira Reforma Ortográfica de repercussão geral, votada em 25 de abril de 1907. Essa proposta foi motivada também pela discussão realizada em 29 de abril de 1898 , na Academia Real das Ciências, na qual se estudou a possibilidade de as duas academias elaborarem conjuntamente um projeto de simplificação e uniformização da ortografia da língua portuguesa. A respeito disso, havia, entre os brasileiros, aqueles que acreditavam que a iniciativa de qualquer decisão oficial não deveria partir do Brasil, mas de Portugal.

Um dos mais veementes defensores da proposta de Medeiros e Albuquerque é José Veríssimo. Para ele, na língua portuguesa não há ortografia, pois os escritores mais representativos da literatura moderna portuguesa têm, cada um, a sua grafia especial. E de cada escritor português ou brasileiro se pode dizer o mesmo. Há pelo menos um ou alguns vocábulos que cada um deles escreve a seu modo. Argumenta que no Rio de Janeiro ou em Lisboa, cada jornal, cada oficina, cada tipografia tem o mesmo modo peculiar de grafar; chama-se pitorescamente "a ortografia da casa” (cf. Veríssimo, 1977, p. 103).

Assevera que esses fatos são causados por jamais ter havido uma autoridade na Academia de Ciências de Lisboa que determinasse ou assentasse a nossa ortografia. Os escritores mais eminentes não se preocupavam com norma, deles vinha o exemplo da anarquia ortográfica. Para o autor, o fato de uma língua não ter ortografia representa um mal do ponto de vista da educação pública, e uma inferioridade para uma língua de gente civilizada.

Desse modo, a Reforma assinada por Medeiros e Albuquerque vem ao encontro das idéias defendidas por Veríssimo, pois os prin- 
cipais objetivos da proposta eram contribuir para a simplificação imediata da ortografia, já que sugeria a redução do volume de grafemas utilizados e a tentativa de uniformização dialetal. Além disso, destaca-se, a base do projeto era de uma ortografia sônica que tentava atribuir a cada letra um som, visando ao ideal de pronúncia brasileira. A solução encontrada pelo reformista é a adoção de um padrão de pronúncia estabelecido por meio de uma norma culta. No entanto, como ressalta Cavaliere (2000), o caráter insatisfatório dessa solução se dá devido ao conceito de norma no início do século XX, que considera desejável o padrão linguístico da região sudeste do país, em especial do Rio de Janeiro, o que dava um aspecto artificial à grafia de muitas palavras em outras regiões.

Gonçalves Viana rejeita a reforma brasileira por não dizer respeito às realidades fonéticas do português de Portugal além de submeter os portugueses ao português do Brasil. Já o grupo de opositores brasileiros não era contra a reforma por estarem de acordo com o sistema vigente, o etimológico; o que eles criticavam eram as incoerências existentes na obra de Medeiros e Albuquerque.

Laet, o maior adversário da simplificação ortográfica e também o maior contestador da Reforma votada pela Academia Brasileira, questiona, por exemplo, a resolução por parte do reformador de eliminar da escrita a letra $y$, mas que seja mantida em palavras de origem indígenas, como Catumby, Javary. “(...) ora, isto é a mais inqualificavel das inconsequencias: physica, por exemplo, elles não admittem que se escreva com 'y'; mas Catumby deve conservar o seu 'y', por ser palavra de procedencia indigena! Póde haver cousa mais tola?” (Laet, apud Cândido Figueiredo, 1929, p. 122).

Evidencia-se, nesse caso, a inconsistência da Reforma, pois a preservação do $y$ em palavras de origem tupi não se justifica sequer pela etimologia, pois se trata de uma língua ágrafa.

Sob a discussão da aprovação da Reforma proposta, Ruy Barbosa, Salvador de Mendonça e Sylvio Romero apresentam um projeto substitutivo com a finalidade de manter a pureza do vernáculo e sistematizar a ortografia. As articulações apresentadas pelo gru- 
po reformista primaram por abordar aspectos não citados por Medeiros e Albuquerque, em vez de apenas atacar as falhas do antecessor e defender o sistema etimológico. Mesmo porque sabiam que parte da culpa da desordem ortográfica era proveniente da etimologia infundada.

Sendo assim, na ata da sessão de 4 de julho de 1907 vem relatada a discussão geral dos projetos de reforma ortográfica. A Academia Brasileira opta por contemplar os dois projetos apresentados, ou seja, o Substitutivo de Salvador Mendonça, em vez de ocupar o lugar do projeto de Medeiros e Albuquerque, na realidade o completou. Cumpre salientar, porém, que se tratava de uma reforma que se limitava apenas à redação de livros e revistas da própria Academia.

Os expedientes da Academia foram cenário de longas discussões a respeito da Reforma, as quais se mostravam imperfeitas e lacunares. Com o término da discussão dos projetos, a Academia Brasileira tornou pública, em 1907, a reforma aprovada, a qual pouco se distancia da sugerida por Medeiros e Albuquerque e da Substitutiva.

Verifica-se que, embora a Reforma de 1907 não tenha ultrapassado os limites da Academia, representou um marco bastante significativo na história da ortografia brasileira, pois, além de a questão ser tratada com seriedade e maior cientificidade por diversas autoridades no assunto, foi amplamente discutida. Desse modo, apresentou-se mais coerente que aquelas que a antecederam. Ainda que, em certo sentido, se mostrasse complexa e pouco abrangente, desta vez estava respaldada e aprovada pela Academia Brasileira de Letras, além de ser reconhecida em Portugal.

Enquanto no Brasil as discussões sinalizavam para a simplificação ortográfica, em Portugal a falta de sistematização evidenciavase cada vez mais, refletindo, inclusive, nas publicações oficiais, em especial no Diário das Câmaras Legislativas, onde cada deputado e cada senador exigiam que os respectivos discursos mantivessem o sistema ortográfico por eles adotado. Em tal situação, a Imprensa 
Nacional solicitou providências do Governo, no sentido de se uniformizar a ortografia das publicações oficiais. Na medida em que cabia ao Governo a função de solucionar a questão para as escolas e outros estabelecimentos que dele dependiam, tratou-se de contatar as personalidades que teriam competência e autoridade sobre o assunto.

Em consequiência disso, formou-se em Portugal uma Comissão Oficial, nomeada para esse fim sob indicação do Conselho Superior de Instrução Pública, da qual fizeram parte alguns cientistas que, dentro e fora do país, eram considerados especialistas na ciência da linguagem. Dentre eles, Gonçalves Viana, a maior autoridade portuguesa em filologia românica no conceito dos mais entendidos, Adolfo Coelho e Leite de Vasconcelos foram incumbidos de fixar as bases da ortografia portuguesa, as quais deveriam ser adotadas nas escolas, nos documentos e nas publicações oficiais.

A reforma proposta, embora aprovada oficialmente, não se impunha a ninguém, fora dos meios oficiais, porém, era tão fundamentada que em pouco tempo difundiu-se e passou a ser adotada pela maioria dos escritores e jornalistas portugueses. Faltava, no entanto, estreitarem-se as relações luso-brasileiras, já que as vantagens de se evitarem discordâncias entre as duas nações eram reconhecidas, pois não fazia sentido numa mesma língua haver maneiras diferentes de grafar, dependendo da nacionalidade de quem escrevia.

Em virtude disso, embora a Academia de Ciências de Lisboa não tivesse a responsabilidade no referido plano de uniformização ortográfica aprovado pelo governo, estando apenas envolvida na produção do futuro Diccionario da Academia, empenhou-se para que a Academia Brasileira se inteirasse do assunto, inclusive posicionandose sobre o sistema gráfico a ser adotado na obra. Para tanto, em uma das sessões estiveram presentes os brasileiros João Lúcio de Azevedo e Assis Brasil.

Entretanto, o tão esperado acordo ortográfico não se firmou nesse momento. Por motivos que fogem da responsabilidade das duas Academias, apenas a Academia de Ciências de Lisboa, de acor- 
do com o Parecer da Comissão Ortográfica de 11 de setembro de 1911, aderiu ao sistema proposto. Note-se que a referida Reforma pouco se distanciou da adotada pelo Brasil, em 1907, pelo menos na essência.

A boa repercussão da obra apresentada por Gonçalves Viana, em 1904, o impulsionou, ao lado de Vasconcelos Abreu, a realizar o também exemplar Vocabulário Ortográfico e Ortoépico da Língua Portuguesa, em 1909. Foi justamente a conciliação dessa obra com a Ortografia Nacional que embasou a elaboração da ortografia simplificada, oficializada na reforma de 1911.

Tanto na Reforma Ortográfica Brasileira, quanto na portuguesa, ocorre a manifestação do mesmo ideal linguíístico. Nesse sentido, ambas dão nova feição à ortografia dos dois países, pois marcaram a definitiva sistematização da grafia. Apesar de apresentarem divergências como a opção brasileira, em 1907, por eliminar as consoantes geminadas e, a portuguesa, em 1911, de mantê-las, como elemento indicador de boa pronúncia, apontam para o fim da desordem ortográfica, que mantinha a grafia associada apenas à vontade do escritor.

Após cinco anos de existência da Reforma Ortográfica Brasileira, a Academia Brasileira de Letras julga ser necessário empreender alguns ajustes no sistema vigente. Desse modo, após algumas discussões, Silva Ramos é nomeado responsável por direcionar a questão. A partir da nomeação, recorre à Reforma portuguesa para fazer as devidas adequações na grafia usada no Brasil, a qual só se consolida em 1915.

O objetivo de Ramos era harmonizar as duas reformas, fazendo com que desaparecessem as diferenças insignificantes que separavam as duas Academias. Para tanto, apresentou à Academia Brasileira de Letras, em 31 de julho de 1915, proposta de pequenas mudanças na grafia em vigor, cabendo a redação definitiva a João Ribeiro.

Na sessão, estiveram presentes dez membros, dos quais apenas um rejeitou o parecer. $\mathrm{O}$ encarregado de levar a notícia à Aca- 
demia de Ciências de Lisboa foi Cândido Figueiredo. Ficou, em seguida, estabelecido que o Colégio Pedro II deveria recomendar aos alunos aquela grafia, sem, todavia, torná-la obrigatória, pois os candidatos à admissão já vinham com conhecimentos definidos sobre a ortografia desde aulas primárias.

A resolução de 1915 provocou grandes discussões. O grupo nacionalista reagiu à decisão tomada, revogando a adoção do modelo luso na ortografia brasileira. No entanto, a implantação do modelo luso era questão de tempo, pois os que detinham o poder de formar os novos usuários da língua escrita já haviam adotado o sistema simplificado.

Assim, em 30 de abril de 1931, por meio do Decreto ${ }^{\circ} 20$ 108, firma-se o primeiro Acordo Ortográfico luso-brasileiro sobre o uso da ortografia nas repartições públicas e nos estabelecimentos de ensino; com isso, oficializa-se, no Brasil e em Portugal, a ortografia simplificada.

Porém, ainda hoje, a ortografia unificada luso-brasileira não foi definitivamente alcançada. Houve várias tentativas de acordos ortográficos, sendo a última em 1990. É fato que não é possível a elaboração de uma reforma que atenda aos anseios de todos os usuários. Vale lembrar que qualquer sistema gráfico é uma forma convencional de representar o que é falado e, conseqüientemente, a representação entre o escrito e o sonoro não é unívoca. Além disso, uma língua de longa tradição escrita possui hábitos gráficos que foram consagrados pelo uso.

\section{CONSIDERAÇÕES FINAIS}

Para finalizar, apresento uma reflexão sobre o vocábulo "reforma", que ao longo do trabalho me inquietou. O que se vê na ortografia portuguesa do século XX é que se buscava a simplificação ortográfica por meio de normas definitivas de grafar. Para atingir tal objetivo, entre outras coisas, eliminaram-se as consoantes 
geminadas e os exageros etimológicos. Essa eliminação, entretanto, provocou pouca ou nenhuma diferenciação em relação ao que se encontrava em vigor antes. Na verdade, buscou-se apenas a fixação gráfica. Se se pensar no significado de reformar (alterar a forma, reconstruir, emendar), vê-se que de fato ela não ocorreu. O que sucedeu, na realidade, foi a opção de fixação de uma letra em substituição a outra em determinadas palavras.

Nesse percurso analítico, constata-se, a respeito da perspectiva histórica, que os fatos externos à língua interferiram na constituição da ortografia e, no que tange à perspectiva linguiística, a análise propriamente dita das regras ortográficas, verifica-se que antes do Acordo Ortográfico, ora os autores tendiam à ortografia que privilegiava a pronúncia, baseando-se na fala, considerada da classe culta, ora preocupavam-se com a tradição histórica, muitas vezes, beirando o exagero.

Em relação ao sistema ortográfico fonético, vê-se, como ficou evidente no percurso analítico, que sua implantação seria inviável. Nesse sentido, ressalto a impossibilidade de se contemplarem todas as variações existentes, pois, além da variação individual, sabe-se também que o modo de pronunciar varia de acordo com a época, a faixa etária, a localidade geográfica, a condição sociocultural. Se insistíssemos em apagar a história para simplificar a ortografia teríamos de escolher qual forma de pronunciar adotaríamos como modelo. Aqui seria preciso seguir a perspectiva científica da sociolinguiística para abandonarmos velhos preconceitos no momento da escolha. Mesmo assim, sempre que pensássemos em registrar as palavras como aparecem em determinada pronúncia, estaríamos operando sobre uma idealização.

Por outro lado, na mesma medida, a adoção da ortografia etimológica também parece impossível, pois, além de representar um retrocesso ao século XVIII, devido à distância existente entre esse tipo de grafia e os usuários, para que fosse implantada seria necessária uma reforma radical. Além disso, correríamos o risco de elaborar um sistema pseudo-etimológico. Justifica-se essa afirma- 
ção ao lembrarmos que temos como língua de origem o latim vulgar, o qual sofreu alterações fonológicas ao longo do tempo. No entanto, aqueles que tentavam preservar a tradição histórica tinham como referência as formas linguiísticas do latim e do grego clássicos, por meio de textos oficiais e literários. Assim, não importava se determinada letra presente no radical de origem já não representava fonema, o que importava era preservar a ligação entre forma atual e a tradição linguiística do português. Por consequiência, surgiram as letras mudas, os grupos helênicos, a dupla representação vocálica e os demais fatos ortográficos que não correspondem à exata grafia de origem.

Diante disso, evidencia-se que, embora estejamos longe da ortografia ideal, que satisfaça todos os usuários da língua, ao adotarmos a ortografia mista, a qual foi edificada em critérios fonéticos e etimológicos, estabelecida entre Brasil e Portugal a partir do Acordo Ortográfico de 1931, estamos mais próximos do respeito ao uso e à tradição.

Por fim, verifica-se que o caráter ideológico perpassou cada proposta ortográfica, o que se torna claro de autor para autor, a cada época, motivados ou por crenças pessoais ou por estarem envolvidos pela ideologia coletiva. Apresenta-se aqui um fato sociolinguiístico, ideologicamente fundado, que bem reflete a questão de política linguíística e de identidade nacional.

\section{BIBLIOGRAFIA}

ACADEMIA BRASILEIRA DE LETRAS (1943) Pequeno Vocabulário Ortográfico da Língua Portuguesa. Rio de Janeiro: Imprensa Nacional.

AUROUX, S. (1992) Historie des idées linguistiques. Bruxelles: Mardaga.

. (1987) Histoire de sciences et entropie des systèmes scientifiques. In: SCHMITTER, P. (org.). Gescheichte der Sprachtheorie, p. 20-42 (introduction).

BÔSCOLI, J. V. (1885) Orthographia: estudo raciocinado segundo os princípios modernos da sciencia. Rio de Janeiro: Imprensa Nacional.

BURKE, P. (1992) A escrita da história. São Paulo: Unesp. 
Filol. lingüíst. port., n. 9, p. 11-26, 2007.

CARR, E. H. (1982) Que é história. 3. ed. Rio de Janeiro: Paz e Terra.

CAVALIERE, R. (2000) Fonologia e morfologia na gramática científica brasileira. Rio de Janeiro: Editora da Universidade Federal de Fluminense.

COSTA, J. C. (1989) Pequena história da República. São Paulo: Brasiliense.

COUTINHO, I. de L. (1976) Pontos de gramática histórica. 7. ed. Rio de Janeiro: Ao Livro Técnico.

FALCON. F. (1997) História das idéias. In: CARDOSO, C.; VAINFAS, R. (orgs.) Domínios da história: ensaios de teoria e metodologia. Rio de Janeiro: Campus.

FAUSTO, B. (1995) História do Brasil. São Paulo: Edusp FDE.

FÁVERO, L. L.; MOLINA, M. A. G. (2004) História das idéias linguiísticas: origem, método e limitações. Revista da ANPOLL, 16, p. 131-46.

FIGUEIREDO, C. de. (1929) A ortografia no Brasil: história e crítica. Lisboa: Livraria Clássica.

GONÇALVES, M. F. (2003) As idéias ortográficas em Portugal: de Madureira Feijó a Gonçalves Viana (1734 - 1911). Lisboa: Calouste Gulbenkian

. (1992) Madureira Feijó: ortografista do século XVIII - para uma história da ortografia portuguesa. Lisboa: Ministério da Educação. Instituto de Cultura e Língua Portuguesa.

GUIMARÃES, E.; ORLANDI, E. P. (orgs.) (1996) Língua e cidadania: o português do Brasil. Campinas: Pontes.

HENRIQUES, C. C. (2001) Atas da Academia Brasileira de Letras: Presidência Machado de Assis (1896-1908). Rio de Janeiro: Academia Brasileira de Letras.

KEMMLER, R. (2001) Para uma história da ortografia portuguesa: o texto metateórico e a sua periodização do século XVI até à reforma ortográfica de 1911. Frankfurt: Instituto Camões.

LEÃO, J. B. (1878) Coleção de estudos e documentos a favor da refórma da ortografia em sentido sónico. Lisboa: Imprensa Nacional.

. (1875) Considerações sobre a orthographia portugueza. Por memória offrecida ao illmo e exmo, sr. Conselheiro Antonio Rodrigues Sampaio, Ministro e Secretario d'Estudo nos negocios do Reino. Porto: Typografia de Antonio José da Silva Teixeira.

LEMOS. M. (1890) La question de la Réforme ortographique. Paris: Biblioteca Nacional de Paris.

(1888) Ortografia Pozitiva. Nota avulsa à Tradução do Catessismo Pozitivista de

A. Comte. Biblioteca Nacional de Paris.

LIMA SOBRINHO, B. (1953) A questão ortográfica e os componentes do Brasil. Rio de Janeiro: Academia Brasileira de Letras.

MOLINA, M. G. (2004) Um estudo descritivo-analítico da gramática expositiva (curso superior) de Eduardo Carlos Pereira. Tese (Doutorado) - Universidade de São Paulo.

ORLANDI, E. P. (2002) Língua e conhecimento lingüístico: para uma história da idéias no Brasil. São Paulo: Cortez.

. (2001) História da idéias lingüísticas: construção do saber metalinguiístico

e constituição da língua nacional. Campinas: Pontes; Mato Grosso: Unemat. 
AGUIAR, Monalisa dos Reis. As reformas ortográficas da língua portuguesa: uma análise...

PINTO, E. P. (1992) A língua escrita no Brasil. 2. ed. São Paulo: Ática.

(1988) História da língua portuguesa. São Paulo: Ática.

SILVA. J. J. (1879) $O$ idioma do hodierno Portugal comparado com o do Brasil. Por um brasileiro. Rio de Janeiro: Typografia de Lourenço Winter.

SWIGGERS, P. (1997) Historie de la pensée linguistique. Paris: Presses Universitaires de France.

VERÍSSIMO, J. (1977) A questão ortográfica. In: Estudos de Literatura Brasileira. Belo horizonte: Itatiaia; São Paulo: Edusp.

VIANA, A. R. G.; ABREU, G. V. (1885) Bases da ortografia portuguesa. Lisboa: Imprensa Nacional.

VIANA, A. R. G. (1909) Vocabulário ortográfico e ortoépico da língua portuguesa conforme a ortografia nacional do mesmo autor. Lisboa: Livraria Clássica Editora de A. M. Teixeira.

. (1904) Ortografia nacional: simplificação e uniformização sistemática das ortografias portuguesas. Lisboa: Viúva Tavares Cardoso.

ABSTRACT: In Brazil, the nineteenth century is marked by significant political, social and economic changes. In that context, due to nationalist feelings with regard to political independence, language matters lead to discussion aiming at linguistic independence, and, in consequence, orthographic independence. This paper, which is part of a research project of wider scope, focuses on such questions, which reflect the $19^{\text {th }}$.-century Brazilian's search for a linguistic identity.

KEYWORDS: Portuguese language; orthography; linguistic identity; national identity. 